\title{
Airway response to deep inspiration: role of nitric oxide
}

\author{
R.H. Brown*, W. Mitzner\#
}

Airway response to deep inspiration: role of nitric oxide. R.H. Brown, W. Mitzner. (C) ERS Journals Ltd 2003.

ABSTRACT: Deep inspirations (DI) have been shown to have both bronchoprotective and bronchodilator effects in healthy subjects. The bronchodilator effects of a DI appear to be impaired in asthmatics compared with healthy subjects. This study investigated the role of nitric oxide (NO) in the bronchodilator role of a DI.

In five anaesthetised and ventilated dogs, high-resolution computed tomography was used to measure the changes in airway size after a small $\left(25 \mathrm{cmH}_{2} \mathrm{O}\right)$ and large $\left(45 \mathrm{cmH}_{2} \mathrm{O}\right) \mathrm{DI}$ before and after administering $N^{\mathrm{G}}$-nitro-L-arginine methyl ester to block NO synthesis.

The depth of the inspiratory manoeuvre during a deep inspiration determined the subsequent qualitative behaviour of the airway response. Inflation to relatively high pressure resulted in airway dilation, whereas one to lower pressure leads to airway constriction. When $N^{\mathrm{G}}$-nitro-L-arginine methyl ester was administered, both a large and a small deep inspiration resulted in subsequent airway constriction. These results support the idea that nitric oxide may be a potential bronchoprotective agent in the airways.

Eur Respir J 2003; 22: 57-61.
*Dept of Anaesthesiology and Critical Care Medicine and ${ }^{\#}$ Dept of Environmental Health Sciences/Division of Physiology, The Johns Hopkins University, Baltimore, MD, USA.

Correspondence: R.H. Brown, Physiology, Room 7006, Johns Hopkins University, Bloomberg School of Public Health, 615 North Wolfe Street, Baltimore, MD 21205, USA.

Fax: 14109550299

E-mail: rbrown2@jhem.jhmi.edu

Keywords: Airways, asthma, bronchoconstriction, bronchodilation, high-resolution computed tomography.

Received: October 22002

Accepted after revision: February 252003

This study was supported by National Institutes of Health Grant PO1 HL10342 and ES-03819.
Deep inspirations (DI) have been shown to have both bronchoprotective and bronchodilator effects in healthy subjects [1, 2]. However, the bronchodilator effects of a DI appear to be impaired in asthmatics compared with healthy subjects [2]. In addition, separate experiments by BRUSASCO et al. [3] and BROWN et al. [4] suggest that there are intrinsic differences between the responses to lung inflation in airways from asthmatic and normal subjects. Healthy normal subjects demonstrated bronchodilation after the DI, whereas asthmatic subjects showed further bronchoconstriction after the DI manoeuvre [4].

When considering the effects of a DI, an implicit assumption is that all of the airways are distending to their maximal size at total lung capacity (TLC). However, it was shown previously in a canine model that the degree of static distension of individual airways was highly variable both within and among animals [5]. Fully relaxed airways were quite distensible at low lung volume, but quickly reached a maximal size with no further distension up to TLC. With smooth muscle tone, the airways showed variable degrees of dilation with lung inflation, but full distension of even moderately constricted airways was rarely achieved, even at TLC [5].

In assessing the response of airways to DI, it would therefore seem important to use a consistent and well-defined lung volume history. However, in human subjects it is not routine to measure transpulmonary pressure and often even the duration of the DI is not well characterised. In a recent study, the authors demonstrated that the length of time at TLC could alter the qualitative response of the airways following the DI [6]. Furthermore, the degree of lung inflation during the DI was also shown to affect the subsequent airway response [7]. If the peak inflation pressure during a DI was large $\left(45 \mathrm{cmH}_{2} \mathrm{O}\right)$, the airways distended and then returned slowly, asymptotically approaching the pre-DI size. However, if the peak inflation pressure was small $\left(\leqslant 35 \mathrm{cmH}_{2} \mathrm{O}\right)$ the airways still dilated during the DI, but recovered to a size that was up to $30 \%$ smaller than the pre-DI level. No mechanisms were investigated in that study, but the authors speculated that perhaps a bronchoconstrictor or bronchodilator was released in response to small or large stretches, respectively. In the present study the authors investigated a possible role for nitric oxide (NO) in this differential response to the level of lung inflation during a DI.

\section{Methods}

The study protocol was approved by the Johns Hopkins Animal Care and Use Committee. Five dogs weighing $\sim 20 \mathrm{~kg}$ were anaesthetised with thiopental $\left(15 \mathrm{mg} \cdot \mathrm{kg}^{-1}\right.$ induction dose followed by $10 \mathrm{mg} \cdot \mathrm{kg}^{-1} \cdot \mathrm{h}^{-1}$ i.v. maintenance dose). After induction of anaesthesia, the dogs were paralysed with $0.5 \mathrm{mg} \cdot \mathrm{kg}^{-1}$ of succinylcholine, with occasional supplemental doses as required to ensure no respiratory motion during imaging. Following endotracheal intubation with an endotracheal tube (inside diameter $8.0 \mathrm{~mm}$ ), the dogs were placed in a supine position and their lungs were ventilated with room air using a volume-cycled ventilator (Harvard Apparatus, Millus, MA, USA) at a tidal volume of $15 \mathrm{~mL} \cdot \mathrm{kg}^{-1}$ and a rate of 18 breaths $\cdot \mathrm{min}^{-1}$. A stable depth of anaesthesia was maintained by monitoring heart rate changes and eyelash reflex. 


\section{Imaging and analysis of airways}

High-resolution computed tomography (HRCT) scans were obtained with a Somatom Volume Zoom scanner (Siemens, Iselin, NJ, USA), using a spiral mode to acquire 50 computer tomography images during a $8 \mathrm{~s}$ breath hold (apnoea) at $137 \mathrm{kVp}$ and $165 \mathrm{~mA}$. The images were reconstructed in slices of $1 \mathrm{~mm}$ and a $512 \times 512$ matrix, using a $125 \mathrm{~mm}$ field of view and a high spatial frequency (resolution) algorithm that enhanced edge detection at a window level of -450 Hounsfield units (HU) and a window width of $1,350 \mathrm{HU}$. These settings have been shown to provide an accurate measurement of lumenal size to as small as $0.5 \mathrm{~mm}$ in diameter $[8,9]$. For repeated airway measurements in a given dog within each experimental protocol, adjacent anatomic landmarks, such as airway or vascular branching points, were defined and used to measure the airway size at the same anatomic cross sections.

The HRCT images were analysed using the airway analysis module of the Volumetric Image and Display Analysis image analysis software package (University of Iowa, IA, USA) as previously described and validated $[5,10]$. The HRCT images were transferred to a UNIX-based Sun workstation (Sun Microsystems, Santa Clara, CA, USA). An initial isocontour was drawn within each airway lumen and the software program then automatically located the perimeter of the airway lumen by sending out rays in a spoke-wheel fashion to a predesignated pixel intensity level that defines the lumenal edge of the airway wall. Intra- and inter-observer accuracy and variability of the software program using this HRCT technique in phantoms, consisting of rigid tubes to measure known areas, has been shown previously by the authors [9] and by others [10] to be highly resistant to operator bias.

HRCT does not allow differentiation of the vessel wall from blood. Since the vessel walls are thin compared with the overall size of the vessel, total vessel area was measured to assess changes in vascular volume using the software package noted above. The operator drew a rough isocontour estimate of the total vessel area and the software program automatically located a precise isocontour of the vessel external perimeter as described for the airway lumenal area above. In each dog, 20-33 vessels of $1.2-6.0 \mathrm{~mm}$ diameter, were matched and measured prior to the DI.

\section{Protocol}

Dogs were anaesthetised and ventilated as described above. To standardise lung volume history, the dogs were initially given a DI of both lungs to $35 \mathrm{cmH}_{2} \mathrm{O}$ for $5 \mathrm{~s}$. Then a stable state of airway tone was induced with a continuous $i$.v. infusion of $67 \mu \mathrm{g} \cdot \mathrm{min}^{-1}$ methacholine (MCh; Sigma Chemical, St Louis, MO, USA). The tubing from the ventilator to the endotracheal tube of the animals had an added large bore $\mathrm{Y}$-connector. One branch of the $\mathrm{Y}$ went to the ventilator and the other branch was connected to a constant pressure source set at either 25 or $45 \mathrm{cmH}_{2} \mathrm{O}$. This source consisted of an underwater overflow fed by a line from a high-flow oxygen supply. At the start of scanning, the ventilator was simultaneously shut off, a solenoid valve to the ventilator was closed and another solenoid to the pressure source was opened to the dog for either $10 \mathrm{~s}$ (for $25 \mathrm{cmH}_{2} \mathrm{O}$ pressure) or $30 \mathrm{~s}$ (for $45 \mathrm{cmH}_{2} \mathrm{O}$ pressure). Solenoids were then switched to suddenly expose the trachea to atmospheric pressure and the scans were acquired. Scanning was performed immediately after the DI ( 4 s) and at 30, 60, 90, 120 and $300 \mathrm{~s}$ after the DI. After each scan set was acquired ( $20 \mathrm{~s}$ of apnoea), the ventilation was resumed. The manoeuvre was then repeated, setting the constant pressure source to the alternate pressure. The $25 \mathrm{cmH}_{2} \mathrm{O}$ DI was performed first, followed by the $45 \mathrm{cmH}_{2} \mathrm{O}$ manoeuvre, with $\geqslant 10 \mathrm{~min}$ between manoeuvres. The lung inflation manoeuvres were then repeated after $N^{\mathrm{G}}$-nitro-L-arginine methyl ester ((L-NAME) Sigma Chemical) was administered by $i$. v. infusion $\left(50 \mathrm{mg} \cdot \mathrm{kg}^{-1}\right)$. To measure the size of the completely relaxed airways, the dogs received $0.2 \mathrm{mg} \cdot \mathrm{kg}^{-1}$ of atropine at the end of the experimental protocols. Previous work has demonstrated that this dose of atropine abolishes all cholinergic smooth muscle tone in dogs [5].

\section{Analysis}

The initial airway area prior to the DI was defined as $100 \%$. The airway lumenal areas were expressed as a per cent of this initial area (dependent variable). Each airway in each dog served as its own control. Generalised analysis of variance was used to compare the airway size between the two DI pressures before and after the administration of L-NAME, and at each time point (independent variables). Fisher's protected least significant difference, Scheffe and Bonnferroni/ Dunn corrections for multiple pairwise comparisons were used. In addition, paired t-tests were used to compare the changes in vessel size before and after L-NAME. $p \leqslant 0.05$ was considered significant.

\section{Results}

In each dog, 23-39 airways, ranging 1.2-8.5 $\mathrm{mm}$ in diameter, were matched and measured during MCh infusion. MCh infusion at the chosen rate caused stable airway constriction to $37 \pm 1 \%$ (mean \pm SEM) of their completely relaxed size. All subsequent measurements were referenced to their baseline (pre-DI) size with $\mathrm{MCh}$ that was defined as $100 \%$. At the first (4 s) measurement after the DI, the mean \pm SEM airway area as a per cent of baseline area prior to the DI was $133 \pm 3$ and $180 \pm 4 \%$ of pre-DI for the 25 and $45 \mathrm{cmH}_{2} \mathrm{O}$ DIs, respectively. The airway area after the $45 \mathrm{cmH}_{2} \mathrm{O}$ DI was significantly greater than the airway area after $25 \mathrm{cmH}_{2} \mathrm{O}$ DI $(\mathrm{p}<0.0001$; fig. 1). During the 5-min interval following the DI, the airway size decreased in a quasiexponential manner. However, there was a qualitative difference in the response of the airways to the DI depending

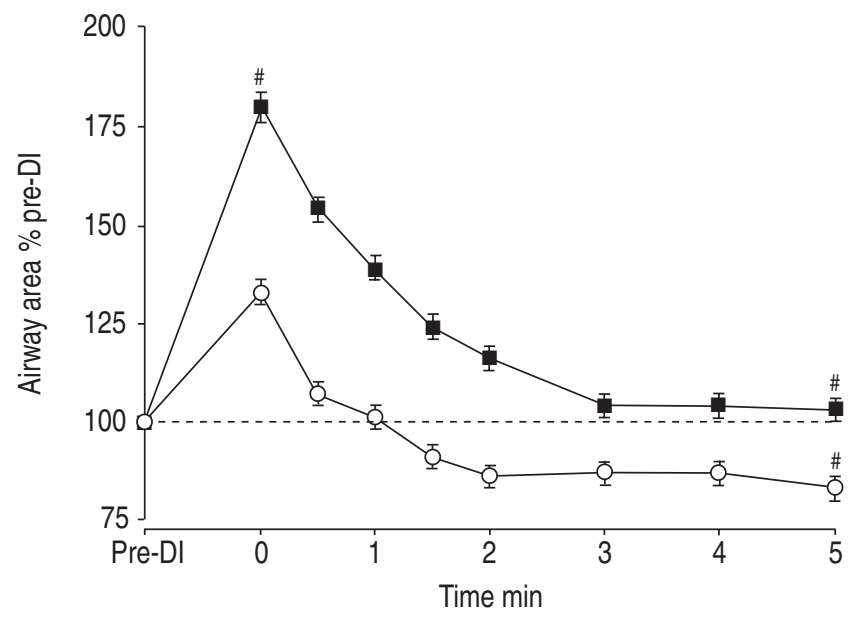

Fig. 1. - Per cent change in mean \pm SEM airway area immediately after a deep inspiration (DI) to a peak inflation pressure of $25 \mathrm{cmH}_{2} \mathrm{O}(\bigcirc)$ and $45 \mathrm{cmH}_{2} \mathrm{O}(\mathbf{\square}){ }^{\#}: \mathrm{p}<0.0001$. 
on the size of the DI. For the larger DI $\left(45 \mathrm{cmH}_{2} \mathrm{O}\right)$, the airway size remained above the baseline airway area for the entire measurement period. At $5 \mathrm{~min}$, the airway area was $103 \pm 3 \%$ of pre-DI, which was not different from the pre-DI value ( $\mathrm{p}=0.26$; fig. 1 ). In contrast, for the smaller DI $\left(25 \mathrm{cmH}_{2} \mathrm{O}\right)$, the airways actively contracted to a smaller area than at the pre-DI baseline. At $5 \mathrm{~min}$, the airway area was $83 \pm 3 \%$ of the pre-DI airway area $(p<0.0001$; fig. 1$)$. The airway size at $5 \mathrm{~min}$ was also significantly different between both pressures $(\mathrm{p}<0.0001)$.

After administration of L-NAME, the vessels' area decreased significantly by $21 \pm 1 \%$ compared with baseline $(\mathrm{p}<0.0001)$, and the airways dilated significantly from $37 \pm 1$ to $60 \pm 1 \%(\mathrm{p}<0.0001$ compared with baseline airway size prior to L-NAME) of their completely relaxed size.

At the first (4s) measurement after the DI, the mean airway area as a per cent of post-L-NAME baseline area prior to the DI was $118 \pm 3$ and $125 \pm 7 \%$ of pre-DI for the 25 and $45 \mathrm{cmH}_{2} \mathrm{O}$ DIs, respectively and these values were not significantly different ( $\mathrm{p}=0.37$, fig. 2 ). During the 5 -min interval following the DI, the airway size decayed to a value smaller than the pre-DI size, but, unlike the situation prior to L-NAME, there was no qualitative difference in the response of the airways to the DI depending on the size of the DI. For both the 25 and the $45 \mathrm{cmH}_{2} \mathrm{O}$ DIs, the airways were actively contracted at $5 \mathrm{~min}$ to $94 \pm 2$ and $81 \pm 2 \%$ of pre-DI airway area for the $25(\mathrm{p}=0.0001$ compared with pre DI) and $45 \mathrm{cmH}_{2} \mathrm{O}$ DIs, respectively $(\mathrm{p}<0.0001$ compared with preDI, fig. 2).

\section{Discussion}

In previous studies, the authors have demonstrated that the manner in which a DI was performed could determine whether the airways responded with a subsequent constriction or dilation. If the DI was performed in a brief period to a relatively small inflation pressure, then airway constriction was observed. However, if the lungs were expanded to a higher pressure for a longer period of time, then the airways remained dilated for many minutes after the manoeuvre [6, 7]. This behaviour may result from two distinct processes, one being a passive viscoelastic stretching of the airway muscle that takes a long time to recover, and the other reflecting some degree of active constriction in response to the lung



Fig. 2. - Per cent change in mean \pm SEM airway area immediately after a deep inspiration (DI) to a peak inflation pressure of $25 \mathrm{cmH}_{2} \mathrm{O}(\mathrm{O})$ and $45 \mathrm{cmH}_{2} \mathrm{O}(\boldsymbol{\square})$ after $i . v$. administration of $N^{\mathrm{G}}$-nitro-L-arginine methyl ester . ${ }^{\#}$ : $<<0.0001 ;$ : $\mathrm{p}=0.0001$. inflation. The present study was designed to test whether NO may be important in the response of the airways to this deep inspiratory manoeuvre. To this end, the experiment compared the airway response to DIs performed at both a large and small maximal inflation pressure.

The current results not only confirmed previous observations by the authors showing that the extent of lung inflation during a DI had a major effect on the subsequent airway size, but also clearly showed that NO appeared to play a role in this response. A large DI initially caused airway dilation and the airways stayed slightly dilated even at 5 min post-DI. However, a small DI caused less initial airway distension and subsequent airway constriction over time. After administering L-NAME to the dogs, the large DI resulted in smaller peak airway distension and also caused a subsequent airway constriction, similar to that normally observed only with the smaller DI inflation. These results suggested that a sudden large inflation of the lung may normally result in release of NO that acutely dilates airway smooth muscle. If this increase in NO was blocked, an intrinsic constrictor response was unmasked. Smaller lung inflations may be insufficient to cause this release of NO.

$\mathrm{NO}$ is a ubiquitous molecule throughout the body that serves several biological functions. One well-documented function of $\mathrm{NO}$ is as a vasodilator [11, 12], and although there is some evidence that $\mathrm{NO}$ can also act as a bronchodilator, this remains controversial [13-17]. NO is synthesised from L-arginine by one of three NO synthase enzymes, which then diffuses into cells and acts through a guanylcyclase mechanism to relax smooth muscle. L-NAME is an NO synthase inhibitor and administration of L-NAME has been widely used to block NO synthesis in vivo. Thus, i.v. infusion of L-NAME in dogs should block the production of $\mathrm{NO}$ in the airways and pulmonary vessels causing constriction. Although under baseline conditions a $21 \%$ constriction in the pulmonary vessels was observed, the average dilation of the airways was $62 \%$. The reason for this unexpected behaviour of the airways is unclear, but it was consistently found in all animals. One possible contributing factor was that the constricted vessels led to a mechanical dilation of the airways via an interdependence mechanism. In previous work studying the effect of vascular engorgement on airways, the authors observed a substantial narrowing of the airways when the vessels were engorged [18]. Although the authors would predict the opposite effect on airways when the vessels are constricted, it is unlikely that the magnitude of this effect could account for the entire increase in airway size. Another contributing factor may be a decrease in cardiac output caused by the pulmonary vascular constriction, leading to a decreased venous return. Such a decrease in systemic blood flow to the airways may lead to a decrease in the delivery of MCh to the airways. This possibility is supported by the work of WAGNER and MiTZNER [19], using a sheep model of airway constriction. When infusing MCh at a constant concentration into the airways through the bronchial circulation, a decrease in bronchial blood flow caused a decrease in airway resistance [19]. Any decrease in cardiac output in animals in this study would likely be reflected in a proportional decrease in bronchial blood flow and thereby decrease the available $\mathrm{MCh}$ in the airway wall. This effect may also be exacerbated by a direct effect of blocking NO synthesis on the bronchial vasculature.

Of even more relevance than the baseline changes after the administration of L-NAME, were the airway responses to DI. After L-NAME, the post-DI airway constriction normally observed only after a small DI now also occurred even after the large DI. Furthermore, the peak recorded distension of the airways after both small and large DIs was reduced compared with baseline values. This latter observation may 
result from the airways being more dilated after the L-NAME. That is, as the airways enlarge and get closer to their maximal size, their ability to dilate, given the same distending force, should decrease. While this mechanism can partially explain why the airways dilate less during the DI manoeuvre, the question still remains as to why the airways now constrict following the DI.

One explanation for this post-DI constriction, suggested in a previous study by the authors [7], was that a contractile mediator is being released in a small stretch of the lung and airways. Such a contractile stimulus would be present with both large and small inflations, but with large inflations, the larger physical distension would be more than sufficient to counterbalance this constrictor effect. A specific mediator was not proposed in this previous work. However, recently an idea was proposed that NO may normally be released during a DI to prevent airway constriction [20]. It was also suggested that a DI may lead to bronchoprotection because of the release of NO to minimise subsequent airway constriction to $\mathrm{MCh}$ challenge. The result could be consistent with this hypothesis, if it assumed that contracted airways have a myogenic response to stretch [21]. A small DI may be insufficient to release enough NO to prevent the subsequent bronchoconstriction caused by the myogenic stretch response. With a large DI, increased amounts of NO are released, which counteracted the smooth airway constriction, allowing the airways to remain dilated. After L-NAME, the peak distension of the airways was similar with both pressures, and since there was no NO released, the airways constricted in both cases. This explanation is speculative at this time, both because NO in the airways was not measured and because there is scant evidence that airway smooth muscle shows an active myogenic constriction to stretch in vivo. However, previous in vitro work with canine bronchial segments clearly demonstrated that contraction can occur in response to airway distension [22], but the extent of this effect in vivo has not been evaluated.

The levels of peak inflation used in the current study were well within the range that can be obtained in humans. Although pleural pressure was not measured, the approximate transpulmonary pressures can be estimated from a previous study where such measurements were performed [5]. In that work, when the airway pressure was $36 \mathrm{cmH}_{2} \mathrm{O}$, the transpulmonary pressure was $23 \mathrm{cmH}_{2} \mathrm{O}$. With a simple linear extrapolation, it was estimated that the transpulmonary pressures at each of the airway pressures used in this study were 17 and $30 \mathrm{cmH}_{2} \mathrm{O}$.

There is little relevant experimental evidence in the literature that has attempted to address the size of DI on subsequent airway tone. Several current clinical investigations have focused on single or repetitive DIs as a means of preventing or reversing bronchoconstriction [1-3, 23]. In general, the nature of the DIs in most clinical studies is not explicitly specified, but they are usually brief and sigh-like, typically in the order of only a few seconds. How these results relate to the paradoxical airway narrowing sometimes seen in asthmatics following a DI [3, 4, 24-30] remains uncertain. Perhaps asthmatic airways are stretched too little during the manoeuvre and behave like the low pressure groups in the present work. BROWN et al. [4] have studied the ability of a DI to distend the airways of normal healthy volunteers compared with mild asthmatics subjects at baseline and after increased tone [4]. A DI distended the airways of healthy and asthmatic subjects to a similar extent. Furthermore, it was observed that after constriction had already been induced by MCh, a deep inspiration resulted in bronchodilation in the healthy subjects, but further bronchoconstriction in the asthmatics, consistent with a loss of or insensitivity to a bronchodilator, such as NO.

In summary, it has been confirmed that the size of the depth of the inspiratory manoeuvre during a deep inspiration determined the subsequent qualitative behaviour of the airway response. Inflation to relatively high pressure resulted in airway dilation, whereas one to lower pressure led to airway constriction. Furthermore, when $N^{\mathrm{G}}$-nitro-L-arginine methyl ester was administered to block nitric oxide, both a large and a small deep inspiration led to subsequent airway constriction. These results support the idea of nitric oxide as a potential bronchoprotective agent in the airways.

\section{References}

1. Scichilone N, Kapsali T, Permutt S, Togias A. Deep inspiration-induced bronchoprotection is stronger than bronchodilation. Am J Respir Crit Care Med 2000; 162: 910-916.

2. Scichilone N, Permutt S, Togias A. The lack of the bronchoprotective and not the bronchodilatory ability of deep inspiration is associated with airways hyperresponsiveness. Am J Respir Crit Care Med 2001; 163: 413-419.

3. Brusasco V, Crimi E, Barisione G, Spanevello A, Rodarte JR, Pellegrino R. Airway responsiveness to methacholine: effects of deep inhalations and airway inflammation. $J$ Appl Physiol 1999; 87: 567-573.

4. Brown RH, Scichilone N, Mudge B, Diemer F, Permutt S, Togias A. High resolution computed tomographic evaluation of airways distensibility and the effects of lung inflation on airway caliber in healthy subjects and individuals with asthma. Am J Respir Crit Care Med 2001; 163: 994-1001.

5. Brown RH, Mitzner W. Effect of lung inflation and airway muscle tone on airway diameter in vivo. J Appl Physiol 1996; 80: $1581-1588$.

6. Brown RH, Mitzner W. Duration of deep inspiration and subsequent airway constriction in vivo. J Asthma 2001; 40: 119-124.

7. Brown RH, Mitzner W. Airway response to deep inspiration: role of inflation pressure. J Appl Physiol 2001; 91: 2574-2578.

8. Wood SA, Zerhouni EA, Hoford JD, Hoffman EA, Mitzner W. Measurement of three-dimensional lung tree structures by using computed tomography. J Appl Physiol 1995; 79: $1687-1697$.

9. Herold CJ, Brown RH, Mitzner W, Links JM, Hirshman CA, Zerhouni EA. Assessment of pulmonary airway reactivity with high-resolution CT. Radiology 1991; 181: 369-374.

10. Amirav I, Kramer SS, Grunstein MM, Hoffman EA. Assessment of methacholine-induced airway constriction by ultrafast high-resolution computed tomography. $J$ Appl Physiol 1993; 75: 2239-2250.

11. Haddad E, Lowson SM, Johns RA, Rich GF. Use of inhaled nitric oxide perioperatively and in intensive care patients. Anesthesiology 2000; 92: 1821-1825.

12. Gewaltig MT, Kojda G. Vasoprotection by nitric oxide: mechanisms and therapeutic potential. Cardiovasc Res 2002; 55: 250-260.

13. Brown RH, Zerhouni EA, Hirshman CA. Reversal of bronchoconstriction by inhaled nitric oxide: histamine versus methacholine. Am J Respir Crit Care Med 1994; 150: 233-237.

14. Dupuy PM, Shore PA, Drazen JM, Frostell C, Hill WA, Zapol WM. Bronchodilator action of inhaled nitric oxide in guinea pigs. J Clin Invest 1992; 90: 421-428.

15. Frostell C, Fratacci M-D, Wain JC, Jones R, Zapol WM. Inhaled nitric oxide: a selective pulmonary vasodilator reversing hypoxic pulmonary vasoconstriction. Circulation 1991; 83: 2038-2047.

16. Frostell C, Högman M, Hedenström H, Hedensterna G. Is nitric oxide inhalation beneficial for the asthmatic patient. Am Rev Respir Dis 1993; 147: 515.

17. Hogman M, Frostell CG, Hedenstrom H, Hedenstierna G. 
Inhalation of nitric oxide modulates adult human bronchial tone. Am Rev Respir Dis 1993; 148: 1474-1478.

18. Brown RH, Zerhouni EA, Mitzner W. Visualization of airway obstruction in vivo during lung vascular engorgement and edema. J Appl Physiol 1995; 78: 1070-1078.

19. Wagner EM, Mitzner W. Bronchial circulatory reversal of methacholine-induced airway constriction. J Appl Physiol 1990; 69: 1220-1224.

20. Scichilone N, Pygros G, Kapsali T, et al. Airways hyperresponsiveness and the effects of lung inflation. Int Arch Allergy Immunol 2001; 124: 262-266.

21. Marthan R, Woolcock AJ. Is a myogenic response involved in deep inspiration-induced bronchoconstriction in asthmatics? Am Rev Respir Dis 1989; 140: 1354-1358.

22. Pauwels RA, Kips JC, Peleman RA, van der Straeten M. The effect of endotoxin inhalation on airway responsiveness and cellular influx in rats. Am Rev Respir Dis 1990; 141: 540-545.

23. Malmberg P, Larsson K, Sundblad BM, Zhiping W. Importance of the time interval between FEV1 measurements in a methacholine provocation test. Eur Respir J 1993; 6: 680-686.

24. Fish JE, Ankin MG, Kelly JF, Peterman VI. Regulation of bronchomotor tone by lung inflation in asthmatic and nonasthmatic subjects. J Appl Physiol 1981; 50: 10791086.

25. Orehek J, Charpin D, Velardocchio JM, Grimaud C Bronchomotor effect of bronchoconstriction-induced deep inspirations in asthmatics. Am Rev Respir Dis 1980; 121 297-305.

26. Fish JE, Peterman VI, Cugell D. Effect of deep inspiration on airway conductance in subjects with allergic rhinitis and allergic asthma. J Allergy Clin Immunol 1977; 60: 41-46.

27. Gayrard P, Orehek J, Grimaud C, Charpin J. Bronchoconstrictor effects of a deep inspiration in patients with asthma. Am Rev Respir Dis 1975; 111: 433-439.

28. Wheatley JR, Pare PD, Engel LA. Reversibility of induced bronchoconstriction by deep inspiration in asthmatic and normal subjects. Eur Respir J 1989; 2: 331-339.

29. Beaupre A, Orehek J. Factors influencing the bronchodilator effect of a deep inspiration in asthmatic patients with provoked bronchoconstriction. Thorax 1982; 37: 124-128.

30. Skloot G, Permutt S, Togias AG. Airway hyperresponsiveness in asthma: a problem of limited smooth muscle relaxation with inspiration. J Clin Invest 1995; 96: 2393 2403. 